\title{
REALISMO, EPISTEMOLOGÍA Y CLASES NATURALES EN HILARY PUTNAM*
}

MaURicio BeuChot

Instiruto de Investigaciones FiLológicas

UNAM

En lo que sigue deseamos proponer a Hilary Putnam algunas observaciones y dificultades surgidas de la lecrura de su obra desde nuestra perspectiva aristotélico-tomista. Nos centraremos en la problemática del realismo interno o realismo pragmático, sostenido por Putnam en contra del realismo metafísico. Esa denominación de "realismo metafísico" corresponde más bien a la metafisica del positivismo o cientificismo (según Putnam, a la de Wilfrid Sellars, por ejemplo), que no aceptaba ningún relativismo como compatible con el realismo; pero no parece referirse al realismo aristotélico-tomista. En efecto, el realismo aristotélico-tomista puede hacerse de alguna manera compatible con la admisión de que la verdad es en cierta medida relativa a marcos conceptuales. La cuestión está en decir hasta qué punto, en qué medida, ya que, por una parte, admite la existencia de esencias o naturalezas en las cosas, pero no puede negar que hay un cierto enfoque del cognoscente. El conocimiento, la verdad, se da en el encuentro del hombre y el mundo.

El realismo aristotélico-tomista, efectivamente, no es tan ingenuo como a veces suele pintárselo, como si fuera inmediatista al modo de la teoría marxista-leninista del reflejo. El propio Aristóteles hablaba de dos tipos de verdad, una correspondentista (que aceptaba además de la coherencia) y otra pragmática; la primera era la del libro Gamma de la Metafísica, y la otra era la que él postulaba para la discusión en los Tópicos. Actualmente, dos connotados tomistas han reflexionado mucho sobre ello, y han colocado el conocimiento dentro de un horizonte de significado, dentro de una perspectiva, relativa a marcos conceptuales, a saber: Emerich Coreth y Bernard Lonergan. ${ }^{1}$ Esa idea de horizonte de significado es un horizonte cultural, es equivalente a la idea de marco conceptual que maneja Putnam.

- Agradecemos a Mark Platts y a Adolfo García de la Sienra su lectura crítica de este trabajo.

1 Véase E. Coreth, Metafisica, Ariel, Barcelona, 1964, pp. 227 ss.; id., Cuestiones fundamentales de hermenéutica, Herder, Barcelona, 1972, pp. 89 ss.; B. Lonergan, Insight, Longmans, Nueva York, 1965; id., "Merging Horizons", Continuum, 1973. 
Así pues, como hemos dicho, el realismo es en cierta medida compatible con el relativismo (de marcos conceptuales, lenguajes o teorías); pero el asunto es ver en qué medida. El ser es análogo, la realidad es análoga, por ello el realismo ha de ser análogo; pero en la analogía lo más fácil es señalar lo común, y lo más difícil y decisivo es señalar las diferencias, los límites, el basta dónde. Es lo que ocurre con la admisión del relativismo en el seno del realismo, de la verdad. Un relativismo absoluto es inconsistente, autorrefutante, contradictorio en los términos mismos. Un relativismo relativo no lo es. Ya con que el relativismo no sea absoluto, sino relativo, el aristotélico-tomista siente ganada la partida. Aunque ciertamente es de atender la voz de quienes dicen que el relativismo, por más que se acepte relativo, acaba siendo inevitablemente absoluto. ${ }^{2}$ Pero, una vez que se han aceptado límites para el relativismo, surge la posibilidad del realismo; sólo hay que ver dónde van esos límites, hasta dónde se extiende el margen de relatividad. Ésa es la cuestión.

El límite que nos parece que debe haber en el relativismo es en su aplicación a las clases naturales, que, dicho en terminología aristotélica, son las physeis, las naturalezas, i.e. las esencias. Las esencias no pueden ser relativas, esto es, las clases naturales no pueden ser relativas a marcos conceptuales. Es cierto que se pueden pensar las esencias como puramente nominales, que hay una interpretación nominalista del esencialismo (por ejemplo como la de van Fraassen), ${ }^{3}$ que está muy vinculado al tipo de necesidad o modalidad necesaria que se acepte; pero eso ya no parece compatible con un realismo, tiende al idealismo, en el que las esencias son construidas, según nuestros intereses y puntos de vista conceptuales; tiene que tratarse de esencias reales; y eso hace que la captación de dichas esencias reales (de las clases naturales) sea intuitiva y no relativa a marcos conceptuales, como trataremos de argumentar a continuación.

Putnam sostiene que la verdad es epistémica, esto es, que es relativa a nuestros marcos conceptuales. ${ }^{4}$ Pero creemos que hay en su sistema al menos algo que no puede ser relativo a dichos marcos, sino intuitivo, a saber, las clases naturales. ¿O son las clases naturales relativas a nuestros marcos, y en qué medida! No pueden serlo de manera absoluta; hay al menos un ingrediente

2 Véase B.A. Scharfstein, "On the Rationality of Context, or, How Rational Attention to Context Leads to Total, Irrational Relativity", en S. Boderman, B.A. Scharfstein (comps.), Rationality in Question. On Eastem and Western Views of Rationality, Brill, Leiden, 1989.

3 Véase B. van Fraassen, "The Only Necessity is Verbal Necessity", Journal of Philosophy, no. 74, 1977, pp. 71-85; id., "Essence and Existence", American Philosophical Quarterly Monograph, 1977-1978.

4 Véase H. Putnam, Representación y realidad, Gedisa, Barcelona, 1990, pp. 166 ss. En otro trabajo suyo, The Many Faces of Realism, 2a. impresión, Open Court, La Salle (Ill.), 1989, p. 17, dice que el realismo que él propone (interno o pragmático) no es incompatible con la relatividad conceprual. En este sentido de relativismo conceptual es que dice que la verdad es epistémica. 
cognoscitivo suyo que no lo es. No pueden serlo en cuanto a su concepción (intuición), sino a lo mucho, como dice Mark Platts, ${ }^{5}$ en cuanto a su conceptualización. Ésta sí depende del hombre, es epistémica y cambia históricamente. Pero lo principal de la captación o conocimiento de esas clases naturales -la concepción- no depende del hombre, no es relativa a marcos conceptuales. Por tanto, hay algo por lo menos que no depende de la episteme humana y, por lo mismo, que no puede llamarse epistémico en cuanto a su verdad. El conocimiento de clases naturales no depende de los marcos epistémicos, pues entonces no serían clases naturales, sino artificiales, al menos en alguna medida (la del constructivismo, y ya no hay realismo alguno). $Y$ decir que no todas las clases son artificiales, sino que hay clases naturales, ¿no implica decir que hay clases que no son conocidas en relación con marcos conceptuales, esto es, epistémicamente?

En efecto, Putnam sostiene que la verdad es epistémica. Esto quiere decir que el intelecto interviene de manera "constructiva" (i.e. no meramente receptiva) y determinante en la captación de la realidad; por ello cree que no se puede hablar de un ingenuo realismo "metafísico", sino de un realismo "interno", y desecha la noción de verdad como correspondencia. ${ }^{6}$ De hecho, sugiere abandonar la noción de verdad y quedarse sólo con la de verificación.

En su trabajo The Meaning of "Meaning", Putnam sostiene que el significado no es sólo el sentido o, como él lo expresa, no es sólo una función de lo que sucede en nuestras cabezas, sino que también es cuestión de referencia, la otra parte del significar. $Y$ agrega que la referencia es determinada por prácticas sociales y por paradigmas físicos, y no sólo por lo que sucede en la mente de cada hablante. ${ }^{7}$

Hay, pues, dos elementos en el significado, uno es de sentido o de comprensión, y otro es de referencia. Por eso en "Reference and Understanding" sostiene que cuando se explica no lo que sucede en la mente de los hablantes, sino el éxito del uso del lenguaje, las nociones realistas clásicas de referencia y verdad se vienen abajo. Por eso propone que, en lugar de una semántica de la verdad, se adopte una semántica de la verificación (no en el sentido de la teoría verificacionista del significado, sostenida por Carnap, sino en el sentido que Dummett da a la verificación). Así se podrá dar un modelo de un hablante

5 Véase M. Platts, "Kind Words and Understanding”, Critica (UNAM), vol. XII, no. 36, 1980, pp. 3-29.

6 Véase H. Putnam, Representación y realidad, ed. cit., pp. 173 ss.; id., The Many Faces of Realism, ed. cit., pp. 17 ss.

7 Véase id., El significado de "significado", UNAM, México, 1984, pp. 17 ss. Reafirma esta postura en Representación y realidad, ed. cit., pp. 30 ss. 
del lenguaje en términos de la noción de grado de confirmación (que es más bien grado de verificación). ${ }^{8}$

Pero sostiene además que se puede ser realista aun en este modelo verificacionista. Pues la tesis realista de que hay correspondencia entre las palabras y las cosas no es incompatible con una explicación de la comprensión en términos de verificación o de uso. Tal correspondencia es parte de una teoría explicativa de la interacción de los hablantes con su medio ambiente. En esa teoría, comprender una oración es conocer sus condiciones de verdad, porque saber en qué consiste eso se vuelve ininteligible; por eso se tiene que hacer de modo verificacionista, y por eso propone el realismo interno.

La razón de ese "cambio de realismo" es que el realismo metafísico se derrumba, según Putnam, en varios puntos; pero hay uno principal: el punto en el que se quiere distinguir del realismo peirceano (de que hay una teoría ideal). Otro punto en que el realismo metafísico es incoherente es que dos descripciones o teorías que para el realista duro son incompatibles, para el realista sofisticado sí son compatibles (como un relato en el que el universo es una línea y tiene puntos y otro en el que es una línea y no tiene puntos), y pueden ser mapeados en el mismo objeto real. En una teoría el objeto es un punto, y en la otra es un conjunto de segmentos convergentes de la línea. Así, una propiedad del mundo en sí mismo es que "admite estos mapeos diferentes". "Sin embargo, como dice Nelson Goodman, en una historia así se puede retener el mundo, pero no hay noción inteligible de cómo es el mundo. "Cualquier enunciado que cambie de valor de verdad al pasar de una teoría correcta a otra teoría correcta - p. ej. en una descripción equivalente- expresará sólo una propiedad del mundo relativa-a-la-teoría."10

A esto podríamos decir que el realismo aristotélico sí puede aceptar dos teorías diversas para explicar un fenómeno, siempre y cuando no sean incompatibles. Pero hay que añadir que para esto Putnam se refiere sobre todo a teorías que involucran formalismo matemático, y el uso que hace él de las matemáticas para hablar del mundo real tiene limitaciones. Hay en las matemáticas ( $y$ en la ciencia en general) muchas entidades teóricas o "arbitrarias" que no hay en el mundo real. Serían lo que en el aristotelismo y el tomismo se llama "entes de razón", i.e. construidos o arbitrados por la mente. Por eso nos remitiremos, para presentarle algunas dificultades u objeciones, a ese mundo real cotidiano en el que encontramos sobre todo esos especímenes ontológicos tan innegablemente no artificiales como son las clases naturales. Y si la física actual encuentra muchos problemas parecidos es por su gran matematización.

8 Véase id., "Realismo y razón"; id., El significado y las ciencias morales, UNAM, México, 1991, pp. 141-146.

9 Id., "Realismo y razón", ed. cit., p. 150.

10 Ibid., p. 151. 
Se despegan del mundo real del lenguaje ordinario. Por eso llega a decir Putnam, con base en su consideración de esas teorías coincidentes, que "tantas cosas se vuelven relativas-a-la-teoría, que el mundo acaba por ser un mundo "noumenal" kantiano, una mera cosa en sí. Si uno no puede decir cómo es el mundo, de manera independiente de la teoría, entonces el discurso de todas estas teorías como descripciones del mundo está vacío."ll

Putnam insiste en que el conocimiento de las clases naturales no incluye sin límites la participación epistémica constructiva de la mente humana, i.e. no puede ser un conocimiento a posteriori, como elaboración de teorías. ${ }^{12}$ Hay un conocimiento a priori (en sentido especial) de la clase natural, en el sentido de que es previo a cualquier construcción de teorías. Damos definiciones a priori de las palabras para clases naturales, p. ej. de "agua", "oro", "vaca" y "manzana". Con esas definiciones (i.e. caracterizaciones necesarias y suficientes) hacemos aplicaciones verdaderas (y no sólo justificadas) de tales palabras; y son caracterizaciones a priori, en el sentido de que se supone que son conocidas por cualquiera que las entiende.

Esto viene a decir de alguna manera que primero se fija - al menos parcialmente- la referencia (o extensión) de la palabra de clase natural con un sentido (o intensión) muy pobre, y después se obtiene su sentido definicional o más completo. Pero Platts se pregunta si ese sentido definicional de la palabra de clase natural puede ser a priori en cuanto conocido por cualquiera que entiende dicha palabra de clase natural.

El sentido definicional está dado por la teoría, por la mejcr teoría existente. Pero el usuario no necesita conocer ese sentido definicional para aplicar la palabra competentemente. Lo conocen los expertos; mas, entonces, si ese conocimiento de la teoría no es estrictamente necesario, el uso de la palabra no depende de él, aunque sí depende de un conocimiento que no es relativo a la teoría. Y entonces hay un sector que está libre, que no es relativo a la teoría, que no es epistémico (al menos en ese sentido). No es absolutamente necesario ese conocimiento porque cuando la teoría no existía, la palabra se usaba adecuadamente (claro que podía haber errores, pero no en los casos normales). ¿O puede decirse que el conocimiento que hubiera era la teoría de la que era relativa a esa captación de la palabra de clase y entonces era relativa a una teoría, esto es, siempre epistémica? Eso ya sería demasiado.

Frege - según Dummett - decía que el sentido es la guía hacia la referencia. Aquí no se ve claro si Putnam dice que no hace falta y que primero se tiene la referencia y luego el sentido, o si lo que se tiene después es el sentido

11 lbid., p. 152.

12 Véase id., El significado de "significado", pp. 29-34, donde dice que los términos para clases naturales son designadores rígidos en el sentido de Kripke. 
definicional y no esa parte del sentido que no es técnico (o teórico), que se tiene previamente a la referencia (y entonces se salvaguarda la tesis de Frege).

Parece haber un conocimiento primero de la palabra de clase natural por definición ostensiva de algún paradigma o estereotipo, en lo cual consiste la descripción estereotípica. Y eso no puede estar epistémicamente determinado en el sentido de ser relativo a una teoría, porque todavía no la hay (a menos que se llegue a decir que no hay experiencia sin teoria porque se toma como teoría cualquier preconocimiento, por ejemplo las pautas culturales o las creencias individuales). Habría que preguntarse: 〈la captación de clases naturales es relativa a una teoría siempre? 'En qué medida? El conocimiento escasísimo que el hombre de las cavernas tiene de la clase natural agua, ies ya una teoría? 'O se le puede llamar teoría en algún sentido? Si se dice que es epistémico porque hay facultades o capacidades epistémicas en el hombre, como su estructura cognoscitiva, es un sentido muy pobre de "epistémico" o de "relativo a una teoría".

Como bien dice Platts, aun cuando se requiera que los hablantes sepan algo sobre los tigres (estereotípicos) para adquirir la correspondiente palabra, "no se sigue que hay algo, alguna cosa o un conjunto de cosas, que se 'requie$r e$ ' que se sepan" (p. 16). Además, se pueden tener no conocimientos, sino creencias, y el que uno tenga creencias desde las cuales ve las clases naturales no basta para hacer epistémica la verdad y relativa-a-teorías la realidad. Si se ha de rechazar el "dar cuenta descriptiva" o las "teorías descriptivas" de los nombres propios (como hace Putnam siguiendo a Kripke), también hay que rechazar las "teorías descriptivas" de las palabras de clases naturales. Incluso lo más frecuente es que hablantes competentes no puedan ni dar reglas a base de sentidos definicionales, ni exhibir un estado cognitivo más "informativo". Sólo hay la posibilidad de adscribirles plausiblemente actitudes proposicionales, pero no creencias sobre teorías, p. ej. sobre la estructura molecular del agua.

Platts introdujo en 1980 (p. 24) una expresión útil: no preguntar si "limón" tiene el mismo significado que hace doscientos años, sino "iexpresa 'limón' ahora el mismo concepto que hace doscientos años?” Y distingue conceptos de concepciones. La concepción es el conjunto de creencias sobre las propiedades que han de tener los objetos para ser identificados. Como lo señala Platts, hay dos extremos: el idealismo extremo, para el que cualquier diferencia de concepción implica una diferencia de conceptos; y el realismo extremo, para el que ninguna diferencia de concepción implica diferencia de conceptos. Creemos que un realismo intermedio - que no sería "interno", ni dejaría completamente de ser metafísico- podría sostener que ciertamente los cambios en la concepción afectan nuestra posesión de los conceptos, pero sin que los conceptos variaran completamente por ellos, y, por consiguiente, sin que las verdades sobre los objetos naturales dependieran completamente $o$ 
fueran relativas a las teorías, esto es, no estarían completamente determinadas por lo epistémico, habría un núcleo ontológico o metafisico que permanecería intacto.

Esto por lo que hace a la semántica de las palabras de clases naturales y al realismo epistemológico que implican. Ahora queremos tratar, finalmente, otro problema que Platts señala. Dice que cada definición de palabras de clase natural incluye "lo que llamaré, intuitivamente y sin explicación, al menos una palabra de clase natural de nivel-más-elevado: 'líquido', 'metal', 'animal' y 'fruta'", por ejemplo (pp. 4-5). Ciertamente da la impresión de que están en cierta aglomeración sin el orden deseado. Aquí sería de mucha utilidad introducir una reflexión acerca de cierta gradación de niveles o tipos lógicos que podrían diferenciarse. Un ejemplo de esto es la teoría de los predicables o categoremas de Aristóteles, que estratifica los elementos de las definiciones de acuerdo con su tipo lógico y además su mayor o menor relación con la esencia. De acuerdo con el tipo lógico, los clasifica según una mayor o menor universalidad, como en el género, la especie y la diferencia especifica, que son los elementos de la definición real esencial; por ejemplo, en el caso de "vaca", el género es "animal", la diferencia es "rumiante" y la especie es la conjunción de ambos, a saber, del género y la diferencia, determinando la especie que los zoólogos llaman "vacca" o "bos communis". De acuerdo con la mayor o menor relación con la esencia, los anteriores predicables (género, diferencia y especie) son los esenciales, y además están el propio y el accidente. Los propios son cualidades que, aun cuando no son esenciales, suelen acompañar a esa clase; en el caso de la vaca, sería el mugir, por ejemplo (extrañaría una vaca que no mugiera, aunque no es esencial a ella para que sea vaca, pues podría tratarse de una vaca muda); y luego vienen los predicados accidentales, que pueden darse o no sin que se deje de pertenecer a esa clase natural; por ejemplo, una vaca sigue siendo vaca si le falta un cuerno, o una pata, o la cola, o si es pinta o negra, gorda o flaca, etcétera. Obviamente los "etcéteras" tienen que pertenecer a estas propiedades accidentales, no a las esenciales, que son necesarias para caracterizar a la clase en cuestión. En otras palabras, hecha esta gradación, la definición habrá de tener forzosamente los elementos esenciales para dar a conocer la palabra de clase natural, y los "etcéteras" podrán referirse sólo a los elementos accidentales, que son innumerables, pero que sólo amplían o mejoran nuestro conocimiento de esa clase, mas no lo determinan. 